\title{
O CRIME DE ESTUPRO NA REDE MUNDIAL DE COMPUTADORES
}

Adriana Baker Goveia Araujo

Universidade do Oeste Paulista - UNOESTE, Curso de Direito, Presidente Prudente, SP. E-mail: adrianabgaraujo@gmail.com

\section{RESUMO}

O presente trabalho teve por objetivo realizar um estudo jurídico sobre o crime de estupro e a possibilidade de sua aplicação por meio da ferramenta virtual (internet). Outrossim, este projeto foi desenvolvido através de bibliografias e artigos eletrônicos, realizando-se um estudo pelo método hipotético-dedutivo e contenda dialética. Data vênia, o enquadramento do crime de estupro perpetrado no ambiente virtual só se tornou possível em decorrência da Lei no 12.015/2009, à qual alterou o artigo 213 do Código Penal, onde para a configuração de tal crime (estupro) não mais se faz necessário o contato físico entre o autor e a vítima (cópula integral ou parcial). Conquanto, perfaz a imprescindibilidade da tipificação de um artigo específico para tal eventualidade em decorrência da imperiosidade de uma pena mais branda, justamente por não se efetivar o contato físico entre o sujeito ativo e o sujeito passivo.

Palavras-chave: Estupro. Atentado violento ao pudor. Internet. Rede mundial de computadores. Ato libidinoso.

\section{STUPER CRIME ON THE WORLD COMPUTER NETWORK}

\begin{abstract}
The objective of this study was to carry out a legal study on the crime of rape and the possibility of its application through the virtual tool (internet). Also, this project was developed through bibliographies and electronic articles, being carried out a study by the hypothetical-deductive method and dialectic contention. As of today, the framework of the crime of rape perpetrated in the virtual environment was only possible as a result of Law no. 12.015 / 2009, which amended article 213 of the Criminal Code, where for the configuration of such crime (rape) is no longer done physical contact between the perpetrator and the victim is necessary (integral or partial copula). However, it is essential to characterize a specific article for such an eventuality due to the imperiousness of a milder sentence, precisely because physical contact between the active and the passive subject is not effective.
\end{abstract}

Keywords: Rape. Violent assault on modesty. Internet. World Wide Web. Libidinous act. 


\section{INTRODUÇÃO}

É sabido que a sociedade coeva é diferente dos indivíduos que existiam no início do processo evolutivo da humanidade, em uma época em que as residências ainda eram cavernas e não se ponderava sobre direitos e obrigações. Não existindo um sistema de governo ou um sistema jurídico para o qual os oprimidos pudessem recorrer, onde os seres humanos não possuíam um raciocínio lógico adequado sobre o significado de suas ações. Uma era primitiva, à qual restou consolidada, posteriormente, a capacidade de adaptação, conhecimento e evolução da raça humana.

Este constante processo evolutivo da humanidade, tanto cultural, intelectual e tecnológico, corrobora a necessidade de novos direitos a serem instituídos, com o desígnio de garantir segurança social e jurídica, para que não restem brechas expostas a interpretações análogas e equivocadas por parte dos operadores do direito; bem como permaneça claro para a sociedade a existência de um ordenamento jurídico que acompanha firmemente o seu desenvolvimento em todos os seus âmbitos.

Portanto, em decorrência de fatos recentes advindos no país sobre o respectivo tema deste estudo, se faz necessário a realização de uma análise jurídica a qual abarque a prática da conduta típica do estupro através da rede mundial de computadores.

\section{METODOLOGIA}

O presente trabalho será desenvolvido por meio de bibliografias, legislações e artigos eletrônicos, averiguando duas áreas que se interligam atualmente: o direito e a informática, onde se efetivará um estudo pelo método hipotético-dedutivo e contenda dialética. Sobrevindo um exame no ordenamento jurídico brasileiro sobre a possibilidade da incidência da temática abordada, ampliando as possiblidades de interpretações da área jurídica.

\section{RESULTADOS}

Após a realização de um estudo sobre a temática abordada, o qual envolveu o ordenamento jurídico brasileiro e a rede mundial de computadores, restou consolidada a possibilidade da prática do crime de estupro por meio da internet. Porém, perfaz o entendimento de que é necessário a criação de um artigo específico na lei para tal conduta típica, para que não possua uma pena tão severa quanto a do agente ativo que toca a vítima (artigo 213 do CP). Data vênia, o objeto de estudo demonstrou um retrocesso por parte dos legisladores e uma falta de entendimento pelos operadores do direito; os quais devem acompanhar a evolução da sociedade.

\section{DISCUSSÃO}

Lamentavelmente, mesmo após séculos de evolução, os seres humanos ainda são capazes de realizar ações abomináveis e repugnantes apesar de sua racionalidade. Sendo que entre estes atos execráveis e desprezíveis se encontram aqueles os quais se classificam como dos crimes contra a dignidade sexual, um instituto ao qual se fez necessário à existência em decorrência dos altos índices de violência sexual perpetrados.

Logo, o estupro é uma conduta classificada como típica no ordenamento jurídico brasileiro, estando expresso no Código Penal, Título VI dos crimes contra a dignidade sexual, bem como no Capítulo I dos crimes contra a liberdade sexual, artigo 213 do referido instituto.

Sobre o tema pondera Cezar Roberto Bitencourt (2017, pág. 48):

A Lei n. 12.015/2009 alterou o Título VI do Código Penal, que passou a tutelar a dignidade sexual, diretamente vinculada à liberdade e ao direito de escolha de parceiros, suprime, de uma vez por todas, a superada terminologia "crimes contra os costumes". Na realidade, reconhece que os crimes sexuais violentos ou fraudulentos atingem diretamente a dignidade, a liberdade e a personalidade do ser humano. 
Importante ressaltar que a Lei no 12.015/2009 modificou o artigo 213 do Código Penal, na acepção de que para a configuração do crime de estupro não se faz necessário que efetivamente advenha à conjunção carnal (cópula), ou seja, o contato físico; bastando um toque voluptuoso do autor da infração penal no sujeito passivo, ou até mesmo por observar a vítima a realizar determinados atos libidinosos obrigados pelo sujeito ativo. Neste sentido discorre Damásio de Jesus (2014, pág. 128):

Para a caracterização do crime exige-se, em primeiro lugar, a prática de conjunção carnal. Por conjunção carnal entende-se a cópula normal, ou seja, o relacionamento sexual normal entre homem e mulher, com a penetração, completa ou incompleta, do órgão masculino na cavidade vaginal. É a introductio penis in vaginam. Não se compreendem na expressão outros atos libidinosos ou relações sexuais anormais, tais como o coito anal ou oral, o uso de instrumentos ou dos dedos para a penetração no órgão sexual feminino, ou a cópula vestibular, em que não há penetração. Nesses casos, todavia, haverá estupro, tendo em vista que o tipo penal, com a modificação provocada pela Lei no 12.015, de 2009, também inclui na disposição o cometimento de "outro ato libidinoso".

Anteriormente a Lei no 12.015/2009, o crime de estupro era caracterizado somente pela conjunção carnal; já a conduta típica do atentado violento ao pudor consistia na prática de qualquer ato libidinoso diverso da cópula. Logo, ocorreu a junção destas duas tipificações no artigo 213 do Código Penal.

Redação anterior - Estupro Art. 213. Constranger mulher à conjunção carnal, mediante violência ou grave ameaça: Pena - reclusão, de 6 (seis) a 10 (dez) anos. Paragrafo único. (Revogado pela Lei n. 9.281, de 4-6-1996).

Redação anterior - Atentado violento ao pudor Art. 214. Constranger alguém, mediante violência ou grave ameaça, a praticar ou permitir que com ele se pratique ato libidinoso diverso da conjunção carnal: Pena - reclusão, de 6 (seis) a 10 (dez) anos. Parágrafo único. (Revogado pela Lei n. 9.281, de 4-6-1996.).

Essa alteração provou ser de extrema importância, tendo um valor significante, pois por meio dela se deixou de fazer distinção entre os crimes de estupro e atentado violento ao pudor, os acoplando em uma única tipificação penal (nomenclatura). Data vênia, na legislação anterior, o estupro só era configurado quando efetivamente acontecia à conjunção carnal, qual seja a penetração do pênis na vagina (total ou parcial); deste modo, só podia ser praticado por homem contra mulher. Enquanto que, a conduta típica de atentado violento ao pudor, consistia na execução de qualquer ato libidinoso (sexo anal, oral, introdução do dedo na vagina ou no ânus da vítima etc.), podendo ser cometido por ambos os sexos. Atualmente, entretanto, haverá estupro, quer tenha havido conjunção carnal, quer tenha sido praticado qualquer outro tipo de ato sexual (Gonçalves, 2017).

Deste modo, é evidente que a definição do crime de estupro está no entendimento de que ele se configura existindo a prática da conjunção carnal total ou parcial (introdução do pênis na vagina), ou qualquer ato libidinoso. Destarte, advindo obrigatoriamente sobre violência ou grave ameaça do sujeito ativo sobre a vítima, a constrangendo, incidindo ou não o contato físico entre o autor da conduta típica e o sujeito passivo; não olvidando, que este constrangimento pode acontecer fisicamente ou psicologicamente. Assim sendo, a finalidade de alteração da Lei, além de punir severamente tornando o regulamento mais rígido e amplo (união do estupro com o atentado violento ao pudor) visou proteger a liberdade sexual de cada indivíduo; neste sentido arrazoa Renato Marcão e Plínio Gentil (2014, pág. 46):

Liberdade sexual é categoria mais concreta, que significa uma esfera de ação em que o indivíduo - e só ele - tem o direito de atuar, e atuar livremente, sem ingerências ou imposições de terceiros. A liberdade sexual diz respeito diretamente ao corpo da pessoa e ao uso que dele pretende fazer. Ao punir condutas que obriguem o indivíduo a fazer o que 
não deseja, ou a permitir que com ele se faça o que não quer com o próprio corpo, a norma penal está tutelando sua liberdade sexual.

O estupro praticado por meio da rede mundial de computadores não é uma nova conduta típica, ao contrário, é o crime de estupro disposto no artigo 213 do Código Penal; porém, praticado através da internet. Possuindo as mesmas elementares, verbos e demais peculiaridades da referida conduta criminosa.

Não se tratando de um novo crime ou do que a mídia tem divulgado com a nomenclatura de "estupro virtual"; é apenas um crime que existe há séculos, mas executado através de ferramentas tecnológicas, e que por este fato deve receber uma tipificação própria, para uma maior clareza de suas elementares e uma pena mais branda em virtude de não incidir o contato físico entre o autor e a vítima.

Portanto, a sua conceituação está na sujeição da vítima ao praticar qualquer ato libidinoso diante de uma câmera, sejam fotos ou vídeos, em tempo real ou não, os quais serão enviados posteriormente para o autor. Incidindo tais atos obrigatoriamente sobre violência ou grave ameaça do sujeito ativo, o qual constrange a vítima, não ocorrendo o contato físico entre o autor da conduta típica e o sujeito passivo; o que também caracteriza o crime de estupro de acordo com as alterações realizadas no dispositivo (junção do crime de estupro com o delito de atentado violento ao pudor), in verbis:

\section{Estupro}

Art. 213. Constranger alguém, mediante violência ou grave ameaça, a ter conjunção carnal ou a praticar ou permitir que com ele se pratique outro ato libidinoso:

Pena - reclusão, de 6 (seis) a 10 (dez) anos.

$\S 1^{\circ}$ Se da conduta resulta lesão corporal de natureza grave ou se a vítima é menor de 18 (dezoito) ou maior de 14 (catorze) anos:

Pena - reclusão, de 8 (oito) a 12 (doze) anos.

$\S 2^{\circ}$ Se da conduta resulta morte:

Pena - reclusão, de 12 (doze) a 30 (trinta) anos.

Após estas breves explanações, a principal indagação ainda é como seria possível a perpetuação do crime de estupro no âmbito virtual. Pois bem, primeiramente perfaz necessária a explicação de determinadas peculiaridades.

Fernando Capez (2017, pág. 21) explana sobre o artigo 213 do Código Penal:

Constranger significa forçar, compelir, coagir alguém a: (a) ter conjunção carnal; ou (b) a praticar ou permitir que com ele se pratique outro ato libidinoso.

a) Conjunção carnal: é a cópula vagínica, ou seja, a penetração efetiva do membro viril na vagina.

b) Ato libidinoso: compreende outras formas de realização do ato sexual, que não a conjunção carnal. São os coitos anormais (por exemplo, a cópula oral e anal). Pode-se afirmar que ato libidinoso é aquele destinado a satisfazer a lascívia, o apetite sexual. Cuida-se de conceito bastante abrangente, na medida em que compreende qualquer atitude com conteúdo sexual que tenha por finalidade a satisfação da libido. Não se incluem nesse conceito as palavras, os escritos com conteúdo erótico, pois a lei se refere a ato, ou seja, realização física concreta.

Assim sendo, o ato libidinoso pode ser configurado de forma virtual, pois sua conotação é ampla.

Para um melhor entendimento basta à exemplificação do sujeito ativo que possui um perfil falso em uma rede social na internet, e que se utilizando deste instrumento constrange uma vítima a lhe enviar fotos praticando qualquer ato libidinoso, deste modo, o autor satisfaz a sua lascívia. E foi o que aconteceu recentemente em Teresina no Piauí, onde um homem foi preso suspeito de praticar o estupro através da internet, conforme reportagem de Claudia Collucci (Uol, 2017): 
Embora o "estupro virtual" não esteja previsto no Código Penal, o homem foi enquadrado com base no artigo 213, que versa sobre estupro e prevê a pena para quem obriga alguém a praticar qualquer tipo de ação de cunho sexual, contra sua vontade, sob ameaça ou uso de violência.

Segundo o delegado Ferreira, o crime se caracteriza como estupro, independentemente de ter ocorrido sem a presença física do agressor. "É um estupro ocorrido em ambiente virtual", afirmou, explicando que a configuração do crime ocorreu quando o homem obrigou a mulher a praticar consigo mesma o ato libidinoso. "Ela foi ameaçada, foi constrangida mediante grave ameaça para manter ato libidinoso. Isso caracteriza o crime de estupro", afirmou.

A respeito da desnecessidade do contato físico para a configuração do crime de estupro, salienta Fernando Capez (2017, pág. 23):

A hipótese em comento não se confunde com aquela em que a vítima é obrigada a praticar atos libidinosos em si própria, como a masturbação, para que o agente a contemple lascivamente. Embora nesse caso não haja contato físico entre ela e o agente, a vítima foi constrangida a praticar o ato libidinoso em si mesma. Surge aí a chamada autoria mediata ou indireta, pois o ofendido, mediante coação moral irresistível, é obrigado a realizar o ato executório como longa manus do agente.

Ademais, o estupro de vulnerável também pode ocorrer por meio da rede mundial de computadores (internet); conforme caso verídico ocorrido no Recife, onde o autor do crime foi preso com material pornográfico de 123 (cento e vinte e três) crianças e adolescentes $(G 1,2018)$ :

Polícia Federal (PF) prendeu, no Recife, um homem de 27 anos suspeito de pedofilia. Segundo a corporação, ao menos 123 crianças e adolescentes foram vítimas dele, que costumava conversar com os menores na internet, fingindo ser uma mulher, pedindo fotos nuas e, posteriormente, chantageando-os.

O homem foi autuado pelos crimes de produção, direção, registro, transmissão, publicação, divulgação e armazenamento de cena de sexo explícito ou pornográfica envolvendo criança ou adolescente; estupro virtual de vulnerável. Juntos os crimes chegam a penas de mais de 20 anos de reclusão.

Data vênia, decisões judiciais tem comprovado este entendimento, conforme o Superior Tribunal de Justiça (STJ):

[...]

Consta dos autos ter sido o recorrente preso temporariamente pela suposta prática dos crimes previstos no art. 241-B da Lei n. 8.069/1990 e nos arts. 147, 213 e 158, esse último na forma tentada, todos do Código Penal, porque, "[...] se valendo de aplicativos de redes sociais, em especial, 'Snapchat 'e 'Tinder', convencia as vítimas a enviarem [...] videos íntimos e, de posse de tais videos, [...] coagia ou a lhe mandarem dinheiro ou a praticarem atos sexuais" (e-STJ fl. 16). (Grifo nosso). Impetrado, pela defesa, habeas corpus no Tribunal de origem objetivando a liberdade do ora recorrente, a ordem foi denegada nos termos da seguinte ementa (e-STJ fls. 95/96): HABEAS CORPUS. ARTIGO 241-B, DA LEI 8.069/90, ARTIGOS 147, 213 E 158, ESTE C/C ARTIGO 14, INCISO II, TODOS DO CÓDIGO PENAL. PRISÃO TEMPORÁRIA. LEI 7.960/1989. INDÍCIOS DE AUTORIA E MATERIALIDADE. DILIGÊNCIAS IMPRESCINDÍVEIS PARA AS INVESTIGAÇÕES. POSSIBILIDADE. ORDEM DENEGADA.

1. Havendo indícios probatórios e provas materiais que denotam pertinência acusatória acerca da prática, em tese, de pornografia infantil, ameaça, estupro virtual e tentativa de extorsão contra vítimas no Distrito Federal, cabível a custódia temporária do paciente, mormente diante da pendência de diligências policiais imprescindíveis. (Grifo nosso).

2. Não se vislumbrando, até o momento, a disseminação de pornografia infantil além das fronteiras nacionais, afasta-se a competência da Justiça Federal.

3. Havendo indícios de autoria e materialidade dos crimes de ameaça, estupro virtual e tentativa de extorsão contra vítimas no Distrito Federal, não há falar em incompetência do 
Magistrado deste egrégio TJDFT para processamento do feito, tampouco em ilegalidade da decisão que decretou a prisão temporária. (Grifo nosso).

$[\ldots]$

\section{CONCLUSÃO}

As pessoas não percebem como a internet atua em suas vidas diariamente, desde a compras realizadas até a utilização para uma ferramenta de trabalho. Porém, tal amplitude deixa lacunas para o surgimento de crimes cibernéticos, algo novo para o ordenamento jurídico e para os legisladores.

Diante do exposto, o estupro praticado por meio da rede mundial de computadores é somente uma dentre várias condutas que estão surgindo e que são tipificadas em outros crimes por meio de analogia; e o resultado é uma confusão doutrinária e legislativa.

Porém, apesar destes obstáculos legislativos, o estupro perpetrado por meio da rede mundial de computadores já é uma realidade assídua, à qual aparece frequentemente nos canais de televisão. Logo, se perfaz necessária a criação de um artigo de Lei específico para tal conduta típica; à qual deve ser observada e entendida principalmente pelos operadores do direito, os quais devem sempre estar abertos para novas possiblidades jurídicas.

\section{REFERÊNCIAS}

BITENCOURT, Cezar Roberto. Tratado de direito penal - Vol. 4. 11. Ed. São Paulo: Saraiva, 2017.

BRASIL. Código Penal (1940). Decreto-Lei n² 2.848, de 7 de Dezembro de 1940. Disponível em: < http://www.planalto.gov.br/ccivil_03/decretolei/Del2848compilado.htm>. Acesso em 09 de maio de 2018.

BRASIL. Lei n. 12.015, de 07 de agosto de 2009. Altera o Título VI da Parte Especial do Decreto-Lei $\mathrm{n}^{\circ}$ 2.848, de 7 de dezembro de 1940 - Código Penal, e o art. $1^{\circ}$ da Lei $\mathrm{n}^{\circ}$ 8.072, de 25 de julho de 1990, que dispõe sobre os crimes hediondos, nos termos do inciso XLIII do art. $5^{\circ}$ da Constituição Federal e revoga a Lei $\mathrm{n}^{\circ} 2.252$, de $1^{\circ}$ de julho de 1954 , que trata de corrupção de menores. Disponível em: <http://www.planalto.gov.br/ccivil_03/_ato2007-2010/2009/lei//12015.htm> Acesso em 09 de agosto de 2018.

CAPEZ, Fernando. Curso de direito penal 3. 15. Ed. São Paulo: Saraiva, 2017.

COLLUCCI, Claudia. Polícia prende homem suspeito de praticar estupro virtual no Piauí. Uol, 2017. Disponível em: <http://www1.folha.uol.com.br/cotidiano/2017/08/1908758-policia-prendehomem-suspeito-de-praticar-estupro-virtual-no-piaui.shtml>. Acesso em: 02 de maio de 2018.

PE, G1. Polícia Federal prende no Recife homem com material pornográfico de 123 crianças e adolescentes. G1 globo, 2018.2 Disponível em: <https://g1.globo.com/pe/pernambuco/noticia/policia-federal-prende-no-recife-homem-commaterial-pornografico-de-123-criancas-e-adolescentes.ghtml>. Acesso em: 09 de maio de 2018.

GONÇALVES, Victor Eduardo R. Curso de Direito Penal, parte especial - arts 184 a 359 H. 1. Ed. São Paulo: Saraiva, 2017.

JESUS, Damásio de. Direito penal, 3ำ volume: parte especial: crimes contra a propriedade imaterial a crimes contra a paz pública. 23 Ed. São Paulo: Saraiva, 2014. 
MARCÃO, Renato. Crimes contra a dignidade sexual: comentários ao Título VI do Código Penal. 3. Ed. São Paulo: Saraiva, 2014.

STJ. PET no RECURSO EM HABEAS CORPUS: PET no RHC 91792 DF 2017/0295532-2. Relator: Ministro Antonio Saldanha Palheiro. DJ: 01/02/2018. JusBrasil, 2018. Disponível em: $<$ https://stj.jusbrasil.com.br/jurisprudencia/549507558/pet-no-recurso-em-habeas-corpus-pet-norhc-91792-df-2017-0295532-2>. Acesso em: 15 de maio de 2018. 